\title{
ОЦЕНКА ИНВЕСТИЦИОННОГО РИСКА В ПРИМОРСКОМ КРАЕ "
}

\author{
(c) 2019 Олейник Елена Борисовна \\ доктор экономических наук, профессор кафедры Бизнес-информатики \\ и экономико-математических методов \\ Дальневосточный федеральный университет, Россия, Владивосток \\ E-mail oleinik.elena@gmail.com \\ (c) 2019 Ерёмин Александр Юрьевич \\ магистрант \\ Дальневосточный федеральный университет, Россия, Владивосток \\ E-mail eremin_ai@students.dvfu.ru
}

Предложены агрегированные показатели для оценки инвестиционных рисков. Для перевода показателей в безразмерную шкалу использована специальная функция желательности. Предложен количественный метод расчета весовых коэффициентов частных показателей для расчёта интегрального показателя инвестиционного риска и построена модель его динамики. Предложенный подход может быть использован для оценки инвестиционного риска и эффективности инвестиционной политики любого региона.

Ключевые слова: инвестиционный риск, функция желательности, весовой коэффициент, динамика интегрального показателя, объем инвестиций.

Обеспечение экономического роста региона неразрывно связано с притоком инвестиций. Несмотря на выгодное географическое положение и более диверсифицированную экономику по сравнению с другими регионами Дальневосточного федерального округа, депопуляция, а также нестабильность экономической ситуации в стране не позволяют увеличивать темпы роста привлекаемых средств и поддерживать стабильный уровень притока инвестиций. Для привлечения инвестиций в Приморском крае создано 2 зоны налоговых преференций: свободный порт

Владивосток и оффшорная зона на о. Русском. Особый интерес для инвесторов представляют собой территории опережающего развития, которые должны способствовать изменению структуры экономики Приморского края, сделать ее более рациональной, повысить качество и уровень жизни населения, а также сделать Приморский край привлекательным место не только для инвестиций в сырьевые отрасли, но и в сферу промышленного производства. В таблице 1 представлены основные направления инвестиционных вложений в реализуемые проекты.

Таблица 1. Основные направления инвестирования в экономику Приморского края

\begin{tabular}{|l|c|c|c|}
\hline \multicolumn{1}{|c|}{ Направление инвестирования } & $\begin{array}{c}\text { Число реализуе- } \\
\text { мых проектов }\end{array}$ & $\begin{array}{c}\text { Сумма инвести- } \\
\text { ций, млрд. руб. }\end{array}$ & $\begin{array}{c}\text { Доля в общем } \\
\text { объеме,\% }\end{array}$ \\
\hline Агропромышленный комплекс & 16 & 155 & 8,60 \\
\hline Туристский комплекс & 23 & 302 & 16,75 \\
\hline Рыбохозяйственный комплекс & 16 & 64 & 3,55 \\
\hline Транспорт и логистика & 37 & 977 & 54,20 \\
\hline Лесопромышленный комплекс & 6 & 9,5 & 0,53 \\
\hline $\begin{array}{l}\text { Горно-металлургический и горно-химический } \\
\text { комплекс }\end{array}$ & 14 & 22 & 1,22 \\
\hline Машиностроительный комплекс & 10 & 153 & 8,49 \\
\hline
\end{tabular}

Источник: рассчитано авторами по данным [5-7]

\footnotetext{
* Работа подготовлена в рамках гранта РФФИ № 19-010-00085 «Комплексная оценка структурной динамики экономической системы Дальневосточного региона на основе моделирования результатов стратегических инвестиционных проектов»
} 
Инвестиции играют особую роль в обеспечении экономического роста. Объем и темпы роста инвестиций во многом определяются благоприятным инвестиционным климатом, количественные и качественные аспекты влияния инвестиций на экономический рост региона подробно описаны в [9]. На состояние инвестиционного климата в Приморском крае оказывает влияние множество факторов. Одним из ключевых факторов, влияющих на инвестиционной климат в регионе является инвестиционный риск. Поэтому оценка инвестиционного риска являются актуальной задачей для обеспечения притока инвестиций и экономического роста в любом регионе.

Методология исследования. В научной литературе описаны различные подходы к определению инвестиционного риска $[4,8]$.

С учетом особенностей существующих подходов под инвестиционным риском следует понимать вероятность возникновения непредвиденных потерь в ситуации неопределенности условий инвестиционной деятельности.

Инвестиционный риск характеризует вероятность потери инвестиций и дохода от них. Его можно оценить с помощью интегрального показателя, синтезирующим в себе различные частные видов рисков, характерные для каждого конкретного региона: экономический, финансовый, управленческий, социальный, экологический, криминальный, законодательный и другие. Рассмотрим подробно основные этапы построения интегрального показателя.

1. Определение частных инвестиционных рисков на основе агрегированных показателей. Для оценки инвестиционного риска региона предлагается использовать 9 показателей (таблица 2), формирующих 3 агрегированных показателя риска: экономический, финансовый и криминальный.

Для выражения большого числа показателей в безразмерной шкале от 0 до 1 может быть использована функция желательности, которая также позволяет сравнивать переведенные показатели. Классическая функция желательности, представленная в работе [3] имеет некоторые недостатки. Так как классическая функция является монотонно возрастающей на всей области определения её изменения неравномерны: для объектов, у которых $x$ (приведенные значения параметра $p$ ) относительно близки к 0, различие значений функции желательности будет много

Таблица 2. Показатели для оценки инвестиционных рисков

\begin{tabular}{|c|c|c|}
\hline $\begin{array}{l}\text { Обозначе- } \\
\text { ние }\end{array}$ & Наименование показателя & Характеристика показателя \\
\hline \multicolumn{3}{|c|}{ Экономический риск, $\mathrm{R}_{1}$} \\
\hline $\mathrm{P}_{11}$ & Износ основных фондов, \% & $\begin{array}{l}\text { Характеризует степень изношенности основных произ- } \\
\text { водственных фондов }\end{array}$ \\
\hline $\mathrm{P}_{12}$ & Коэффициент смертности & $\begin{array}{l}\text { Показатель убыли населения. Оценка медицинского и } \\
\text { экологического благополучия края }\end{array}$ \\
\hline $\mathrm{P}_{13}$ & Уровень безработицы, \% & $\begin{array}{l}\text { Показывает процентное отношение числа безработных к } \\
\text { общей численности трудоспособного населения }\end{array}$ \\
\hline $\mathrm{P}_{14}$ & $\begin{array}{l}\text { Коэффициент демографической } \\
\text { нагрузки }\end{array}$ & $\begin{array}{l}\text { Отражает, сколько лиц нетрудоспособного возраста при- } \\
\text { ходится на } 1000 \text { человек трудоспособного возраста }\end{array}$ \\
\hline \multicolumn{3}{|c|}{ Финансовый риск, $\mathrm{R}_{2}$} \\
\hline $\mathrm{P}_{21}$ & Доля убыточных предприятий, \% & $\begin{array}{l}\text { Удельный вес организаций, закончивших год с убытком, } \\
\text { в общем количестве организаций, ведущих предприни- } \\
\text { мательскую деятельность }\end{array}$ \\
\hline $\mathrm{P}_{22}$ & $\begin{array}{l}\text { Задолженность по заработной } \\
\text { плате, тыс. руб. }\end{array}$ & $\begin{array}{l}\text { Численность работников, перед которыми организация } \\
\text { имеет просроченную задолженность по отношению к } \\
\text { общему числу занятых }\end{array}$ \\
\hline $\mathrm{P}_{23}$ & Индекс потребительских цен, \% & $\begin{array}{l}\text { Изменение во времени общего уровня цен на товары } \\
\text { и услуги, приобретаемые населением для непроизвод- } \\
\text { ственного потребления }\end{array}$ \\
\hline \multicolumn{3}{|c|}{ Криминальный риск, $\mathrm{R}_{3}$} \\
\hline $\mathrm{P}_{31}$ & Уровень преступности, штук & $\begin{array}{l}\text { Число зарегистрированных преступлений на } 100000 \\
\text { человек населения }\end{array}$ \\
\hline $\mathrm{P}_{32}$ & $\begin{array}{l}\text { Уровень преступности в экономи- } \\
\text { ческой сфере, штук }\end{array}$ & $\begin{array}{l}\text { Число зарегистрированных преступлений экономиче- } \\
\text { ской направленности на } 1000 \text { человек населения }\end{array}$ \\
\hline
\end{tabular}


больше, чем для объектов, у которых при той же разнице $x$ отдален от 0, что значительно снижает объективность оценки.

В работе [2] для устранения этого недостатка предлагается в качестве функции желательности использовать функцию:

$$
\mathrm{f}(\mathrm{x})=\frac{1}{\pi}\left(\operatorname{arctg}\left(\frac{\mathrm{x}}{3}\right)+\frac{\pi}{2}\right)
$$

где $\mathrm{x}$ - приведенное значение исследуемого параметра объекта.

Функция (1) является монотонно возрастающей на всей области определения, и ее значения лежат в интервале $(0 ; 1)$. В отличии от классической функции желательности возрастает достаточно равномерно. Для $\mathrm{x} \in[-2 ; 2]$ приращение функции не превышает 0,02 , а для $\mathrm{x} \notin[-2 ; 2]$ приращение незначительно и стремится к 0. Таким образом, использование функции (1) в качестве функции желательности предпочтительнее, чем использование классической функции желательности. Функцию (1) предлагается использовать в качестве безразмерной шкалы для оценки каких-либо показателей. Область значений функции разбивается на равные интервалы с шагом 0,2 . При этом каждому фактическому значению функции желательности придается конкретный экономический смысл. Соответствия между значениями функции желательности и характеристиками объекта и основные этапы построения функции желательности подробно описаны в [2]. После расчета функций желательности необходимо найти агрегированные показатели риска Ri используя формулу среднего геометрического, где і изменяется от 1 до 3:

$$
R_{i}=\sqrt[n]{\prod_{j=1}^{n} f_{i j}}
$$

где $\mathrm{f}_{\mathrm{ij}}$ - функция желательности, соответствующая значению Ріj-го показателя риска; $\mathrm{n}-$ количество обычных показателей, входящих в состав агрегированного.

2. Расчет интегрального показателя инвестиционного риска региона.

$$
\mathrm{I}_{\text {risc }}=\sum_{\mathrm{i}=1}^{\mathrm{n}} \mathrm{R}_{\mathrm{i}} \cdot \mathrm{w}_{\mathrm{i}}
$$

где $\mathrm{R}_{\mathrm{i}}$ - значение соответствующего агрегированного показателя; $\mathrm{n}=3$ - это количество агрегированных показателей; $\mathrm{w}_{\mathrm{i}}-$ весовой коэффициент i-го агрегированного показателя $\mathrm{R}_{\mathrm{i}}$.

Для определения весовых коэффициентов мы предлагаем построить обычную регрессию методом наименьших квадратов вида:

$$
\mathrm{V}_{\text {inv }}=\mathrm{a}_{0}+\sum_{\mathrm{i}=1}^{\mathrm{n}} \mathrm{a}_{\mathrm{i}} \mathrm{R}_{\mathrm{i}}
$$

$\mathrm{V}_{\mathrm{inv}}$ - ежегодные значения объемов инвестиций, поступивших в регион. Не все коэффициенты могут быть значимыми, но наша задача - не прогнозирование, а определение весов: нормированные абсолютные значения $t$-статистик для коэффициентов $a_{i}$ и будут весовыми коэффициентами $w_{i}$. Преимущество такого подхода к определению весовых коэффициентов - отказ от экспертных методов ранжирования, при котором часто наблюдается субъективизм и несогласованность мнений экспертов.

3. Полученный интегральный показатель может быть рассмотрен в динамике, что позволит определить его дальнейшую тенденцию. Для прогнозирования интегрального показателя инвестиционного риска региона предлагаем использовать модель Хольта-Уинтерса без учета сезонного эффекта (формулы 5-7).

$$
\begin{aligned}
& \operatorname{Irisc}_{t+h}=l_{t}+h b_{t} \\
& l_{t}=\alpha \operatorname{Irisc}_{t}+(1-\alpha)\left(l_{t-1}+b_{t-1}\right) \\
& b_{t}=\beta\left(l_{t}-l_{t-1}\right)+(1-\beta) b_{t-1}
\end{aligned}
$$

Первое уравнение является основным в данной модели. Оно отражает сам прогноз значения временного ряда Irisc на период $\mathrm{t}+\mathrm{h}$, который можно выполнить на основе данных, имеющихся в момент времени $t ; l_{t}$ моделирует за уровень ряда, a $b_{t}-$ за тренд. Параметр $\alpha-$ это коэффициент экспоненциального сглаживания; $\beta$ - это коэффициент сглаживания тренда. Оба параметра принимают значения на интервале от 0 до 1 . Возможность сделать прогноз имея относительно короткий временной ряд - одно из преимуществ модели Хольта-Уинтерса [1].

Результаты исследования. Источником данных являются материалы сайтов Федеральной службы государственной статистики и ее территориальных органов [4-6]. Все расчеты выполнены в программной среде R-Studio, peзультаты представлены в таблице 3.

На основании данных таблицы 3 можно сделать следующие выводы: наиболее значимое влияние на уровень инвестиционного риска в Приморском крае оказывает криминальный 
Таблица 3. Интегральный показатель инвестиционного риска Приморского края и его прогноз

\begin{tabular}{|c|c|c|c|c|c|c|c|c|}
\hline Год & $\mathrm{R} 1$ & $\mathrm{R} 2$ & R3 & Irisc & Modeling & \multirow{2}{*}{\multicolumn{3}{|c|}{ Дополнения }} \\
\hline 2005 & 0,294 & 0,676 & 0,28 & 0,414 & - & & & \\
\hline 2006 & 0,404 & 0,865 & 0,124 & 0,380 & - & \multirow{2}{*}{$\begin{array}{l}\text { Агрегированные } \\
\text { показатели риска }\end{array}$} & \multirow{2}{*}{ t-statistica } & \multirow{2}{*}{$w_{i}$} \\
\hline 2007 & 0,496 & 0,801 & 0,105 & 0,349 & 0,347 & & & \\
\hline 2008 & 0,469 & 0,752 & 0,172 & 0,374 & 0,317 & R1 - экономический & 0,141 & 0,021 \\
\hline 2009 & 0,349 & 0,805 & 0,353 & 0,506 & 0,400 & R2 - финансовый & 2,263 & 0,338 \\
\hline 2010 & 0,324 & 0,898 & 0,787 & 0,815 & 0,637 & R3 - криминальный & 4,29 & 0,641 \\
\hline 2011 & 0,429 & 0,925 & 0,872 & 0,881 & 1,024 & & & \\
\hline 2012 & 0,449 & 0,915 & 0,85 & 0,864 & 0,946 & & & \\
\hline 2013 & 0,428 & 0,902 & 0,773 & 0,809 & 0,846 & \multirow{2}{*}{$\begin{array}{c}\text { Параметры модели } \\
\text { Хольта-Уинтерса }\end{array}$} & \multirow{2}{*}{ Год } & \multirow{2}{*}{ Прогноз } \\
\hline 2014 & 0,416 & 0,723 & 0,841 & 0,792 & 0,755 & & & \\
\hline 2015 & 0,377 & 0,702 & 0,854 & 0,793 & 0,775 & $\alpha=0,99$ & 2018 & 0,679 \\
\hline 2016 & 0,355 & 0,488 & 0,905 & 0,752 & 0,793 & $\beta=0,04$ & 2019 & 0,642 \\
\hline 2017 & 0,301 & 0,377 & 0,908 & 0,716 & 0,712 & SSE $=0,116787$ & 2020 & 0,605 \\
\hline
\end{tabular}

риск - уровень преступности, в том числе в сфере экономических преступлений. Следующий по значимости - финансовый риск, который характеризуется в частности числом убыточных предприятий и числом «замороженных» по разным причинам инвестиционных проектов. Наименее влиятельным является экономический риск. Наиболее высокий уровень инвестиционного риска наблюдался в 2011-2012 гг.

Динамика расчетных (Irisc) и моделируемых (Modeling) значений интегрального показателя инвестиционного риска, полученных с помощью модели Хольта-Уинтерса представлена на рисунке 1.

В 2006-2010 гг. наблюдался резкий рост интегрального показателя инвестиционного риска, но затем, начиная с 2012 г., имеется устойчивый ниспадающий тренд. Чем объясняется такая динамика? В научной литературе инвестиционный риск определяется как риск обесценивания ка- питаловложений в результате действий органов государственной власти и управления. В Приморском крае, начиная с 2012 г., предприняты активные меры по поддержке инвесторов, было создано Агентство по привлечению инвестиций, которое является сервисным центром, ориентированным на сопровождение инвестиционных проектов с целью быстрого разрешения юридических и технических вопросов. Основные меры, в результате которых произошло уменьшение интегрального показателя инвестиционного риска:

во-первых, государственно-частное партнерство, которое дает возможность переложить первоначальные расходы реализации на частный сектор экономики, поскольку бюджетные возможности ограничены. А интерес инвестора заключается в том, что он получает возможность минимизировать риски и государственные гарантии по обеспечению возврата заемных де-

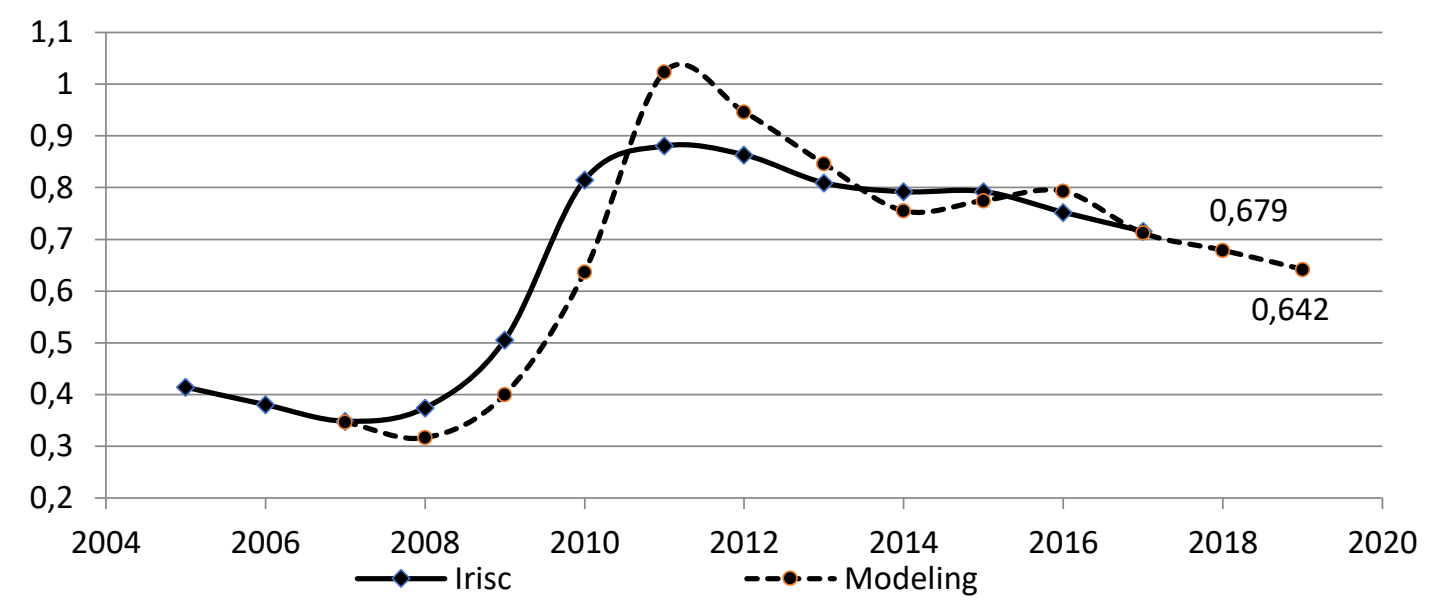

Puc. 1 Динамика расчетных и моделируемых значений интегрального показателя инвестиционного риска в Приморском крае 
нежных средств;

во-вторых, организационное и информационное обеспечение инвестиционной деятельности, в том числе сокращение более чем в три раза сроков подготовки документации для получения разрешения на строительство и подключения к источникам электроэнергии. А также зонирование территории региона: северо-восточная зона определена территорией развития «зеленой экономики»; западная и центральная зоны предполагают развитие сельского хозяйства и добычу полезных ископаемых. В южной зоне планируется территория развития сервисных секторов экономики: финансовых и транспортно-логистических услуг;

в-третьих, поддержка инвесторов на за- конодательном уровне. В Приморском крае в частности гарантируется стабильность условий предоставления господдержки в течение срока окупаемости инвестиционного проекта. Также инвестор сохраняет за собой право дальнейшего обслуживания введенного в эксплуатацию объекта и за счет этого возвращает вложения, а затем и получает прибыль.

Прогнозируемое, стабильно уменьшающееся значение интегрального показателя инвестиционного риска свидетельствует об эффективности проводимой инвестиционной политике в Приморском крае. Предложенный подход может быть использован для оценки инвестиционного риска и эффективности инвестиционной политики любого региона.

\section{Библиографический список}

1 Бабешко, Л.О. Прогнозирование финансово-экономических показателей по разнородным данным / Л. О. Бабешко, В.А. Бывшев.- М.: Русайнс, 2016. - 560 с.

2 Ивашина Н.В. Методика оценки конкурентоспособности регионального рыбного комплекса на основе функции желательности // Вестник ТГЭУ, 2005. № 3.- С. 26-36

3 Любушин, Н.П. Использование обобщенной функции желательности Харрингтона в многопараметрических экономических задачах / Н.П. Любушкин, Г.Е. Брикач // Экономический анализ: теория и практика.2014. - № 18 (370). - С. 2-10

4 Наролина, Ю.В. Инвестиционный потенциал и инвестиционный риск как основные составляющие инвестиционной привлекательности региона /Ю. В. Наролина // Вестник Тамбовского ун-та. - 2009. - № 12.— С. 137-143

5 Официальный сайт инвестиционного агентства Приморского края [Электронный ресурс].- Электрон. дан.- Режим доступа: https://pkia.ru (дата обращения 10.06.2019)

6 Официальный сайт территориального органа Федеральной службы государственной статистики по Приморскому краю [Электронный ресурс].- Электрон. дан.- Режим доступа: http://primstat.gks.ru (дата обращения 12.06.2019)

7 Официальный сайт Федеральной службы государственной статистики [Электронный ресурс]. - Электрон. дан.- Режим доступа: http://www.gks.ru (дата обращения 15.06.2019)

8 Сулоева, С.В. Обзор зарубежной практики оценки инвестиционного климата для привлечения иностранного капитала / С. В. Сулоева, Е.Ю. Михиенкова // Вестник ТГЭУ.-1999. - № 3. - С. 3-10

9 Oleinik E., Zakharova, A. Quantitative and Qualitative Aspects of Influence of the Investments on Economic Growth// International Journal of Economics and Financial Issues. Special Issue for "Fundamental and Applied Research in Economics and Management: New Perspectives”.- 2016.-No 6(S8).- P. 340-345. .- Co-auth.: Zakharova, A. http://www.econjournals.com/index.php/ ijefi/article /view/3763 